\title{
Subarachnoid Hemorrhage and Normal Angiography: Should the Angiogram be Reviewed by a Second Neuroradiologist?
}

\author{
Ashfaq Shuaib, Mary Anne Lee, Robert D. Johns and Harold A. Swanson
}

\begin{abstract}
In recent years there has been a tendency to abandon repeat cerebral angiography in patients with subarachnoid hemorrhage (SAH) if the initial angiogram is normal because prognosis is said to be excellent. Our experience does not support such a conclusion. We report our experiences in 25 patients with SAH, who had a normal initial angiogram. Aneurysms were seen in five of 20 cases when angiography was repeated. On subsequent review of the initial angiograms, the aneurysm was apparent in four of the five cases. When these four initial angiograms were shown to a second observer, unaware of the results of the second study, three of the four aneurysms were correctly identified. We suggest that if, under strong clinical suspicion of SAH, the angiogram is reported as normal the study should be reviewed by a second neuro-radiologist before proceeding to repeat angiography.
\end{abstract}

RÉSUMÉ: Hémorragie sous-arachnoïdienne avec angiographie normale: doit-on demander une revision de l'angiogramme par un deuxième neuro-radiologiste? Depuis quelques années, la tendance est à l'abandon de l'angiographie cérébrale de contrôle chez les patients ayant une hémorragie sous-arachnoïdienne (HSA) si l'angiogramme initial est normal parce que le pronostic en serait excellent. Notre expérience n'appuie pas une telle conclusion. Nous rapportons notre expérience chez une série de 25 patients avec HSA, qui avaient un angiogramme normal initialement. Des anévrismes ont été observés chez cinq des vingt cas lors d'une angiographie subséquente. Quand ces quatre angiogrammes initiaux ont été présentés à un deuxième observateur ignorant les résultats du deuxième examen, trois des quatre anévrismes ont été identifiés correctement. Nous suggérons que, s'il existe une forte présomption clinique de HSA et que l'angiogramme est décrit comme normal, l'angiogramme devrait être présenté à un second neuro-radiologiste avant de répéter l'examen.

Can.J. Neurol. Sci. 1988; 15:413-416

Angiography in Subarachnoid Hemorrhage (SAH) reveals the site of bleeding in $75-90 \%$ of cases. ${ }^{1-7}$ A small proportion of cases with initial normal angiograms may eventually show such rare conditions as small cortical artery rupture, ${ }^{8}$ spinal cord AVM, ${ }^{9}$ extra-medullary aneurysm of the spinal cord, 10 aneurysm of the artery of Adamkiewiez, ${ }^{11}$ and peri-mesencephalic hemorrhage. ${ }^{12}$ The cause in the remaining cases is not clear. The standard practice, where the initial angiogram was normal, has been to repeat the study in 10 to 14 days. The chances of visualizing an aneurysm on the second angiogram is reported to be between 5-10\%. ${ }^{13}$ In recent years, however, a number of publications in the neurosurgical literature would suggest abandoning the need for a second angiogram, as the prognosis after the initial negative angiogram is said to be excellent. ${ }^{14-16}$ Our experience would tend not to support such a conclusion.

The purpose of this communication is to review our experience in patients with normal initial angiograms, and based on our data, suggest some recommendations.

\section{MeTHODS AND ResulTS}

We reviewed the hospital charts of patients with a diagnosis of SAH in the four year period, 1980-84. A diagnosis of SAH was considered only when a typical history of SAH was present and verified by either lumbar puncture and/or CT scan of the head. Patients were excluded if there was a recent history of head injury, blood dyscrasias, primary intracerebral hemorrhage or intracranial malignancy. Two hundred and sixteen patients were identified who fulfilled the above criteria. Pan cerebral angiography was performed in 181 of these patients. Oblique views were carried out in most patients. In 25 patients the angiograms were reported as normal. Twenty of these patients with a normal angiogram had repeat cerebral angiography and an aneurysm was identified in five of the 20 patients. The first angiogram in most patients was done within 24-48 hours of the ictal event and the second study was done between 7-14 days (Table 4). The location of the initially non visualized aneurysms was as follows: Anterior Communicating Artery: 2; Middle

From the Department of Clinical Neurosciences, Foothills Hospital, Calgary

This work was in part presented at the XXI Canadian Congress of Neurological Sciences in London, Ontario June 24-28, 1986

Received February 4, 1988. Accepted April 11, 1988

Request for reprints to: Dr. M.A. Lee, Department of Clinical Neurosciences, Foothills Hospital, Calgary, Alberta, Canada T2N 2 T9 


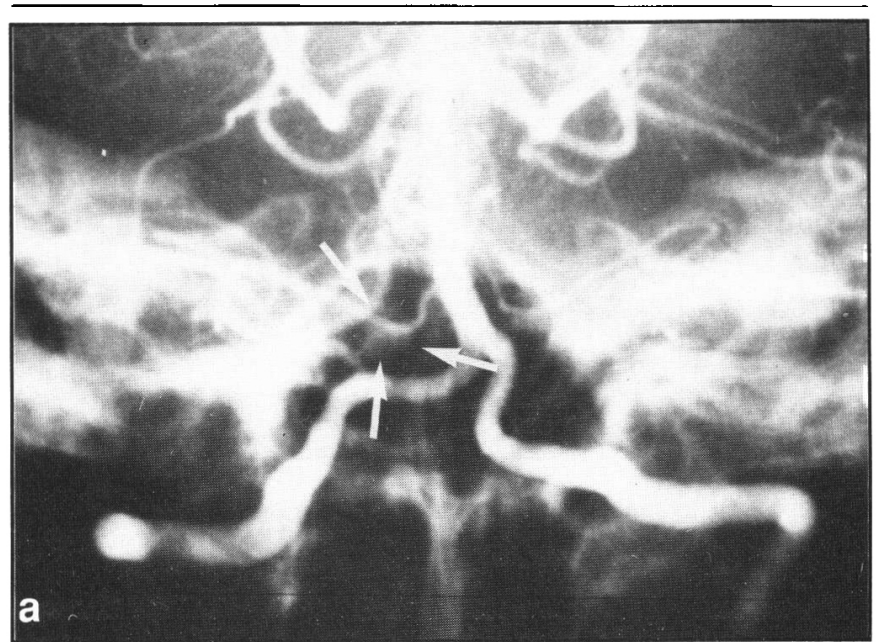

Figure la - Initial angiogram done on the day of admission which was interpreted as normal. Subtraction views were not done.
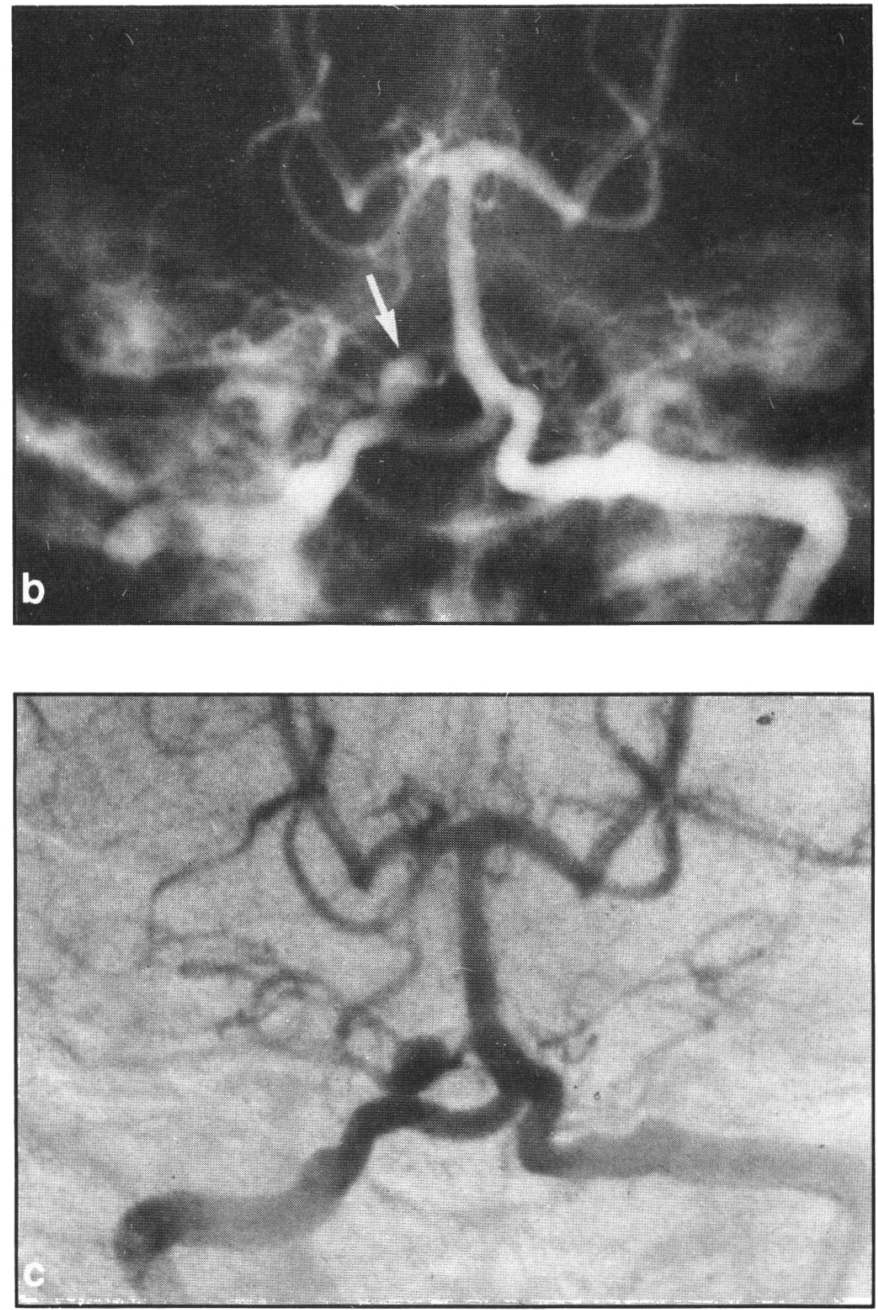

Figure $1 b$ and c. - Repeat study 14 days later showing the aneurysm of the posterior inferior cerebellar artery, which is better defined on subtraction view's.

\begin{tabular}{lc}
\hline Table 1: Overview of Patient Information & \\
\hline \hline Total Patients & 216 \\
Patients undergoing angiography & 181 \\
Normal initial study & 25 \\
Repeat Angiography & 20 \\
Normal second Angiography & $15 / 20$ \\
\hline
\end{tabular}

Table 2: Symptoms and Signs at Admission

\begin{tabular}{lcc}
\hline \hline & $\begin{array}{c}\text { A. Second Angiogram } \\
\text { Normal }\end{array}$ & $\begin{array}{c}\text { B. Second Angiogram } \\
\text { Abnormal }\end{array}$ \\
\hline 1. Headache & $15 / 15$ & $5 / 5$ \\
2. Neck Stiffness & $14 / 15$ & $4 / 5$ \\
3. Level of Consciousness & & \\
$\quad$ Alert & $8 / 15$ & $3 / 5$ \\
$\quad$ Drowsy & $6 / 15$ & $2 / 5$ \\
$\quad$ Comatose & $1 / 5$ & $0 / 5$ \\
4. Nausea/Vomiting & $8 / 15$ & $2 / 5$ \\
\hline
\end{tabular}

Table 3: Eventual Outcome

\begin{tabular}{lcc}
\hline \hline & $\begin{array}{c}\text { A. Second Angiogram } \\
\text { Normal }\end{array}$ & $\begin{array}{c}\text { B. Second Angiogram } \\
\text { Abnormal }\end{array}$ \\
\hline 1. Recovery & & \\
$\quad$ Complete & $13 / 15$ & $3 / 5$ \\
Partial & $2 / 15$ & $2 / 5$ \\
$\quad$ Deaths & $0 / 15$ & $0 / 5$ \\
2. Complications & & \\
$\quad$ Hydrocephalus & $2 / 15$ & $0 / 5$ \\
Spasm (arterial) & $2 / 15$ & $2 / 5$ \\
Infarction & $2 / 15$ & $0 / 5$ \\
\hline
\end{tabular}

Table 4: Timing of Angiography

Second Angiogram Second Angiogram

Normal Abnormal

First Angiogram

(from the onset of SAH) Mean 1.8 days 2 days

(between Ist - 2nd Angio) Mean 14 days 10 days

Range 7-30 days $8-13$ days

Table 5: Findings on CT Scan

\begin{tabular}{lcc}
\hline \hline & $\begin{array}{c}\text { Second Angiogram } \\
\text { Normal }\end{array}$ & $\begin{array}{c}\text { Second Angiogram } \\
\text { Abnormal }\end{array}$ \\
\hline A. Hemorrhage & & \\
$\quad$ I. Focal & $2 / 15$ & $2 / 5$ \\
2. Diffuse $\quad$ Unilateral & $2 / 15$ & $1 / 5$ \\
$\quad$ Bilateral & $3 / 15$ & $1 / 5$ \\
B. None (Normal) & $8 / 15$ & $1 / 5$ \\
C. Hydrocephalus & $2 / 15$ & $0 / 5$ \\
D. Infarction & $2 / 15$ & $0 / 5$ \\
\hline
\end{tabular}


Cerebral Artery: 1; Posterior Cerebral Artery: 1; Posterior Inferior Cerebellar Artery: 1. In two patients the aneurysms were better defined in the second study (Figures $1 \mathrm{a}, \mathrm{b}, \mathrm{c}$ ). Subtraction views were done during the second study and were helpful in making the diagnosis. When the first angiograms were reviewed in retrospect, the aneurysm could be seen in four instances where the initial studies were misread as normal. When these four initial angiograms were shown to a different neuroradiologist, unaware of the results of the second study, three of four aneurysms were correctly identified by the second observer.

The clinical findings on admission, results of cranial CT scans, complications in hospital and eventual outcome are shown in Tables 1 to 5 . It is evident from the tables that based on preliminary investigations and clinical criteria, patients that harbor aneurysms cannot be separated from those that do not.

\section{DISCUSSION}

The initial angiogram was interpreted as normal in $13.8 \%$ (25 of 181) of our cases; this is in keeping with the $10-15 \%$ as in previous reports. ${ }^{1-7}$ Repeat angiography in such cases reveals an aneurysm in $5-10 \%$ of cases, 13 our rate of $20 \%(5$ in 20$)$ is somewhat higher.

In our series, three of four aneurysms, present on the initial angiogram but missed were correctly visualized by a second observer. A review of other publications dealing with normal angiograms in the setting of $\mathrm{SAH}$ also reveal a number of aneurysms that have been initially misread as normal.7,14,17 This has sometimes been called observer-error. ${ }^{17}$ In a study of 219 autopsy cases of SAH, there were 23 cases where the angiograms were read as normal, but aneurysms were evident at autopsy. The cases of non-visualization included six where aneurysms were present at angiography, but were mistakenly read as normal. 17 In Hayward's study of 51 patients, two aneurysms present on initial angiogram but misread as normal were retrospectively identified only after a second angiogram. ${ }^{1}$ In similar circumstances, Forster's et al study of 150 patients, retrospectively identified three aneurysms present on the initial study only after a second angiogram. ${ }^{14}$ To our knowledge, none of the studies to date that were reported as normal have had the initial angiogram reviewed by a second neuroradiologist. Following a review of our data, and earlier reports from the literature, we would recommend that if there is a strong clinical suspicion of SAH and the initial angiogram is reported as normal, the angiogram should be reviewed by a second independent observer. This may well decrease or negate the need for a second angiogram. Subtraction technique has become available in recent years and will prove useful in decreasing the number of false negatives. 18

In one of our five cases, the aneurysm visualized on the second study could not be seen on the initial angiogram, despite careful scrutiny, even in retrospect. The exact incidence of aneurysm visualization on a second study with a normal initial angiogram is difficult to determine, but a review of the literature would suggest that it can often be significant. ${ }^{5,16,19}$ In the cooperative study of intracranial aneurysms and subarachnoid hemorrhage, 477 of 6638 patients with SAH had normal angiograms. Repeat angiography was done in 72 cases, reveal- ing aneurysms in 13 cases (18\%). ${ }^{18}$ Aneurysms were seen in one of 13 cases $(7.6 \%)$ in Spallone et al's study's and two of 17 cases $(11.7 \%)$, in Juul et al's study 16 where angiograms were repeated in the clinical settings of $\mathrm{SAH}$ and normal initial angiograms.

Finally, in the study of Suzuki et al,25 nine of $41(22 \%)$ patients with a normal angiogram and SAH had aneurysms visualized on the second procedure. Angiography was done for a third time in 14 cases, and of these, one (7\%) showed an aneurysm that was not visualized on the previous two studies. In most cases, negative angiograms in the setting of SAH can be explained by temporary aneurysm thrombosis followed by clot lysis and visualization of the aneurysm on subsequent angiography. Other possible causes of non-visualization on angiography include spasm with non-filling, destruction of the aneurysm by hemorrhage, very small aneurysms or poor angiographic technique. ${ }^{25}$

Although some recent studies would suggest the chances of rebleeding to be low, in the order of $1.2 \% 1.20-24$ in cases of $\mathrm{SAH}$, where the initial angiograms are normal, we feel that the risks from repeat angiography are probably still less, especially with better techniques and the availability of new nonionic, low osmolality contrast agents, than the risks associated with missing an aneurysm for which an effective cure could be offered.

\section{ACKNOWLEDGEMENT}

We gratefully acknowledge the help of the Department of Education Resources at the Calgary General Hospital in preparation of this manuscript.

\section{REFERENCES}

1. Hayward RD. Subarachnoid hemorrhage of unknown etiology. J Neurol Neurosurg Psychiatry 1977; 40: 926-931.

2. Andrioli GC, Solar G, Rigobello L, et al. Subarachnoid hemorrhage of unknown etiology. Acta Neurochir (Wien) 1979; 48: 217-221.

3. Hook O. Subarachnoid hemorrhage: prognosis when angiography reveals no aneurysms. A report of 138 cases. Acta Med Scand $1958 ; 162: 493-503$.

4. Locksley HB. Natural history of subarachnoid hemorrhage, intracranial aneurysms and arteriovenous malformations. Based on 6368 cases in the cooperative study. J Neurosurg 1966; 25: 219-239.

5. Eskesen V, Sorensen EB, Rosenorn J, et al. The prognosis in subarachnoid hemorrhage of unknown etiology. J Neurosurg 1984; 61: 1029-1031.

6. West HH, Maui RL, Eisenberg RL, et al. Normal cerebral angiography in patients with subarachnoid hemorrhage. Neurology 1977; $27: 592-594$.

7. Bjorkester G, Halonen V. Incidence of intra-vascular lesions in patients with subarachnoid hemorrhage with four-vessel angiography. J Neurosurg 1965; 23: 29-32.

8. Hochberg FH, Fisher CM, Roberson GH. Subarachnoid hemorrhage caused by rupture of a small superficial artery. Neurology $1974 ; 24: 319$.

9. Herdt D Jr, Chiro G, Doppman JL. Combined arterial and arteriovenous aneurysm of the spinal cord. Radiology 1971; 99: 589593.

10. Hopkins CA, Wilkie FL, Vovis DC. Extra-medullary aneurysm of the spinal cord. J. Neurosurg 1966; 24: 1021-1024.

11. Garcia CA, Dulcey S, Dulcy J. Ruptured aneurysm of the spinal artery of Adamkiewicz during pregnancy. Neurology 1979; 29 : 394-398. 
12. Van Gijn J, Van Dogen KJ, Vermeulen M, et al. Perimesencephalic hemorrhage: a non-aneurysmal and benign form of subarachnoid hemorrhage. Neurology 1985; 35: 493-497.

13. Binet FE, Angluaco EJC. Radiology of intracranial aneurysms. In: Wilkins RH, Rengachary SS, eds. Neurosurgery. McGraw Hill Company 1985; 1348.

14. Forster DMC, Steiner L, Hakanson ML, et al. The value of panangiography in cases of unexplained subarachnoid hemorrhage. $J$ Neurosurg 1978; 48: 712-716.

15. Spallone A, Ferrante E, Palatinsky E. Subarachnoid hemorrhage of unknown origin. Acta Neurochir 1986; 80: 12-17.

16. Juul R, Torbjorn AF, Ringkjob R. Prognosis in subarachnoid hemorrhage of unknown etiology. J Neurosurg 1986; 64: 359-362.

17. Perrett LV, Bull JD. Some aspects of subarachnoid hemorrhage. $\mathrm{Br}$ J Radiol 1959; 32: 85-92.

18. Ziedses des Plantes BG. Subtraction technique. In: Newton TH, Potts DG, eds. Radiology of the skull and brain. C.V. Mosby Company $1974 ; 958-972$.
19. Nishioka H, Torner JC, Graf CJ, et al. Co-operative study of intracranial aneurysms and subarachnoid hemorrhage. A long term prognostic study. Arch Neurol 1984; 41: 1147-1151.

20. Bequelin C, Seiler R. Subarachnoid hemorrhage with normal cerebral panangiography. Neurosurgery 1983; 13: 409-411.

21. Phillips LH, Whisnant JP, O'Fallon MW, et al. The unchanging pattern of subarachnoid hemorrhage in a community. Neurology 1980; 30: 1034-1040.

22. Shepherd RH. Prognosis of spontaneous non-traumatic subarachnoid hemorrhage of unknown cause. A personal series 19581980. Lancet 1984; 1: 777-779.

23. Velghe LE, DeWit P. Cryptogenic spontaneous subarachnoid hemorrhage. Clin Neurol Neurosurg 1983; 85: 139-144.

24. Bjerre P, Videback H, Lindholm J. Subarachnoid hemorrhage with normal cerebral angiography. A prospective study in sellar abnormalities and pituitary function. Neurosurgery 1986; 19: 1012-1015.

25. Suzuki S, Kayanma T, Sakurai Y, et al. Subarachnoid hemorrhage of unknown cause. Neurosurgery 1987; 21:310-313. 